\title{
A Stakeholder Informed Professional Development Framework to Support Engagement with Learning Analytics
}

\author{
Geraldine Gray* \\ Ana Schalk* \\ geraldine.gray@tudublin.ie \\ ana.schalk@tudublin.ie \\ Technological University Dublin \\ Dublin, Ireland
}

\author{
Pauline Rooney \\ Trinity College Dublin \\ Dublin, Ireland \\ pauline.rooney@tcd.ie
}

\author{
Charles Lang \\ Teachers College, Columbia \\ University \\ New York, USA \\ charles.lang@tc.columbia.edu
}

\begin{abstract}
This paper reports on a study aimed at identifying training requirements for both staff and students in higher education to enable more widespread use of learning analytics. Opinions of staff and students were captured through ten focus groups (37 students; 40 staff) and two surveys (1,390 students; 160 staff). Participants were predominantly from two higher education institutions in Ireland. Analysis of the results informed a framework for continuous professional development in learning analytics focusing on aspects of using data, legal and ethical considerations, policy, and workload. The framework presented here differentiates between the training needs of students, academic staff and professional services staff.
\end{abstract}

\section{CCS CONCEPTS}

-Applied computing $\rightarrow$ Education; Computer-assisted instruction; $\bullet$ Human-centered computing $\rightarrow$ Visualization; Interaction design.

\section{KEYWORDS}

Learning analytics, continuous professional development, stakeholder perspectives, higher education

\section{ACM Reference Format:}

Geraldine Gray, Ana Schalk, Pauline Rooney, and Charles Lang. 2021. A Stakeholder Informed Professional Development Framework to Support Engagement with Learning Analytics. In LAK21: 11th International Learning Analytics and Knowledge Conference (LAK21), April 12-16, 2021, Irvine, CA, USA. ACM, New York, NY, USA, 11 pages. https://doi.org/10.1145/3448139. 3448162

\section{INTRODUCTION}

The field of learning analytics has come under increasing focus in higher education, in particular for its potential role in informing and supporting student success initiatives. While the potential value of learning data is well recognised, tapping into this potential requires staff and students in higher education to be confident in

*Both authors contributed equally to this research.

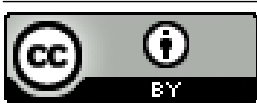

This work is licensed under a Creative Commons Attribution International 4.0 License. LAK21, April 12-16, 2021, Irvine, CA, USA

(C) 2021 Copyright held by the owner/author(s).

ACM ISBN 978-1-4503-8935-8/21/04

https://doi.org/10.1145/3448139.3448162 their use and interpretation of data. There are a range of challenges to be addressed before learning analytics is a valued ubiquitous tool in our pedagogical toolbox, one of which is the continuous professional development (CPD) of staff and students on using, and taking action from, learning analytics [5].

Recognising a deficit of work in the area of CPD for learning analytics, this paper reports on a study that developed a CPD roadmap to support using data in teaching and learning contexts. Specifically, this paper addresses the question: What are the constituents for a CPD framework based on staff and student needs? A needs analysis was conducted with higher education staff and students which considered the role of CPD to increase digital proficiencies in the effective use of learning data to promote student success. Analysis of the results informed the development of a CPD framework in learning analytics, for staff and students, as a guide for educational developers in higher education. The work reported in this paper was completed as part of project DALTAÍ ${ }^{1}$, that also captured opinions on learning analytics more generally.

Section 2 discusses relevant literature in this area. Section 3 describes the methodology used for both qualitative and quantitative analysis of training needs. Section 4 presents the main findings from focus groups undertaken with students and staff from across partner campuses, and a triangulation of the main concordances and differences in staff and student perspectives related to training in learning analytics. Results from staff and student surveys are presented in Section 5, evidencing that many perspectives expressed in focus groups resonated with a larger audience, although some differences are also highlighted. Results are synthesized into a proposed CPD framework covering the main training needs identified by students and staff. This is presented and discussed in Section 6 . Conclusions are given in Section 7.

\section{REVIEW OF RELEVANT LITERATURE}

Although there is wide agreement on the benefits of learning analytics, many institutes still struggle to operationalize learning analytics across campus. There is an increase in the development of Learning Analytics Dashboards (LAD) and other data visualisations in Higher Education, aimed at presenting insights from data in intuitive formats for end users, both staff and students [23]. There is also some evidence of low engagement and sporadic usage of those dashboards [14-16], and a lack of evidence of impact [6, 8]. Data visualisation by nature should be intuitive regarding the information

${ }^{1}$ Daltaí is Irish for students, and an acronym for Developing All Learners Through Analytics Initiative. The project website is: https://daltai-he.ie/ 
being presented. For example, Corrin and Barry [6] reported that students had the ability to interpret feedback via LADs, the difficulty arose in knowing how to act on that feedback. Similarly, Dazo et al. [9] found that in spite of high levels of enthusiasm for LADs, instructors found it hard to relate the data to issues of relevance in their teaching context. Merely providing learning analytics is not enough to empower agency [25]. This highlights a key issue for stakeholders (staff and students), namely, how graphics based on observable data collected in a learning context can be translated to actionable information on the learning process, and so have impact.

Stakeholders must be involved in deriving actionable intelligence as the interpretation of data needs to consider the context that generated it [12], as does identifying the questions and conversations that data can inform [11, 20, 26]. The importance of stakeholder involvement in both identifying relevant questions and resulting actions has been highlighted in a number of studies analysing LAD usage [20,23]. In addition, Aguilar and Baek [1] found that students' reaction to a $\mathrm{LAD}$ was influenced by the design of its presentation, so both designers and educators need to consider the role of an LAD within their learning context, and how its presence may influence student behaviour, positively and negatively.

While we were unable to find comparable CPD frameworks, three recently published learning analytics process models are relevant to CPD. They considered stages of educators' engagement with learning data. Each reflects a different context. Price-Dennis and Lang [19] developed a four-step workflow informed by their work with 30 elementary STEM teachers on data practices. It aimed to demystify a process generally regarded as complex. The first stage, data, considered what can be counted or measured to answer a question; the second stage, process, progressed to extracting meaning from that data; the third stage, knowledge, reflected on what can be inferred from the process that is relevant to the learning context. The final stage considered the actions that can arise from the knowledge. Separately, Verbert, Duval, Klerkx, Govaerts and Santos [27] proposed a model from the perspective of LADs for empowerment rather than automating decisions. Their starting point was existing LADs, however, activities distilled into a similar four stage process. The first stage, awareness, focused on the data itself as it's presented in visualizations; the second stage, reflection, asked questions about the data and its usefulness; the third stage, sense making, was gaining new insights; and the final stage, impact, covered the resulting actions or new understanding that results from reflections. Finally, Wise and Jung [28] also proposed a model for instructional analytics arising from work with staff in higher education. Their model encompassed the four stages in both models above, but grouped them into two stages: sense making covered the first three stages of the previous two models; and pedagogical response covered stage 4 . In their experience, the starting point within sense making may not be the same for all, which concurs with the different starting points in the previous two models. Sense making encompassed identifying areas of curiosity, generating questions, reading the data, and explaining the patterns found. Pedagogical response included taking action, checking impact, reflecting on pedagogy or continuing to monitor a pattern. The three models and their overlaps are depicted in Table 1.
Models of the learning analytics process relate to using data. For other relevant aspects of learning analytics, the extensive engagement with stakeholders completed by the SHEILA project ${ }^{2}$ are worth considering. They highlight that policy, concerns, and legal, ethical \& moral considerations, are also important [24]. Outputs from the SHEILA project include focus groups and survey protocols designed to capture these perspectives on learning analytics.

It must be recognised that not all educators embrace learning analytics, or agree with the need to take part in training they perceive as not directly relevant to their areas of interest and expertise. Mandinach, Freidman and Gummer [17] identified a lack of recognition in schools of education of the importance of data literacy in teacher training. Even for those ready to embrace learning analytics, considering how to tap into the growing volume of data being collected can be a daunting task [19]. Learning from research into technology and tool adoption more generally, successful adoption requires instruments to fit seamlessly into the activities of the professional [18]. This suggests training needs analysis should be cognisant of the role of the educator (identifying the questions or areas of curiosity, and responding to information) versus the role of the learning analyst in presenting intuitive data visualisations that can offer insights that are relevant to those questions [19].

The literature cited above identifies a number of areas of focus when capturing stakeholder perspectives on training requirements. These include stages related to using data, legal and ethical considerations, policy, concerns, and appropriate boundaries between the role of front line staff and that of a learning analyst. The following methodology section outlines how perspectives on these themes were captured to inform a CPD framework.

\section{METHODOLOGY}

The needs analysis for CPD in learning analytics conducted in this study used a mixed-methods approach, combining collection and analysis of qualitative and quantitative data. The first phase consisted of semi-structured focus groups with both staff and students. Focus groups were run in each of the three campuses of Technological University Dublin (TU Dublin) and in Galway-Mayo Institute of Technology (GMIT). Both are Higher Education Institutions (HEIs) in Ireland. The aim of focus groups was to identify preferences and needs in relation to up-skilling and training that may be required to engage with learning analytics. In phase two, surveys were used to collect the opinion of a larger sample of stakeholders on points raised during focus groups. There was a separate survey for staff and students. Both focus groups and surveys were based on the SHEILA $^{2}$ framework protocols. Additional prompts on training were added to the focus group protocols, as detailed in Table 2. Items added to SHEILA surveys are discussed in Section 3.4. This paper focuses on responses relevant to $\mathrm{CPD}$ and training only.

\subsection{Focus Group Administration \& Participants}

Five student and five staff focus groups were held between April and June, 2019, capturing the voices of 37 students and 40 staff members. One staff focus group was run at each campus (four in total), and a fifth focus group was run with members of the

\footnotetext{
${ }^{2}$ SHEILA (Supporting Higher Education to Integrate Learning Analytics) project framework: https://sheilaproject.eu/sheila-framework/
} 
Table 1: Models of learning analytics process

\begin{tabular}{lcccc}
\hline & Stage 1 & Stage 2 & Stage 3 & Stage 4 \\
\hline Price-Dennis and Lang [19] & Data & Process & Knowledge & Action \\
\hline Verbert, Duval, Klerkx, Govaerts and Santos [27] & Awareness & Reflection & Sense-making & Impact \\
\hline Wise and Jung [28] & \multicolumn{2}{c}{$\begin{array}{c}\text { Sense-making: } \\
\text { Curiosity, questions, data }\end{array}$} & Explain patterns & $\begin{array}{c}\text { Pedagogical response: } \\
\text { Action, impact, reflection. }\end{array}$ \\
\hline
\end{tabular}

Table 2: Prompts added to the SHEILA focus group protocols

\begin{tabular}{|c|c|c|c|}
\hline Protocol & Theme & Questions & Prompts \\
\hline $\begin{array}{l}\text { Student } \\
\text { focus } \\
\text { group }\end{array}$ & Training & $\begin{array}{l}\text { Should the uni- } \\
\text { versity provide } \\
\text { you with train- } \\
\text { ing on data lit- } \\
\text { eracy? }\end{array}$ & $\begin{array}{l}\text { Should you get training on how to interpret visual data from a dashboard? } \\
\text { Should you get training on data protection an ethical uses of your personal data? } \\
\text { Would you like training on GDPR covering Consent and Ownership and Autonomy } \\
\text { Should you get training on interpreting statistics or other numeric measurements } \\
\text { derived from your personal data? } \\
\text { Should you get training on the limitations of learning analytics? }\end{array}$ \\
\hline $\begin{array}{l}\text { Staff } \\
\text { focus } \\
\text { group }\end{array}$ & Training & $\begin{array}{l}\text { What training } \\
\text { would be useful } \\
\text { to enable you } \\
\text { engage with } \\
\text { student data? }\end{array}$ & $\begin{array}{l}\text { How to interpret visual data from a dashboard? } \\
\text { Data protection an ethical uses of combining data from different sources, analysis of } \\
\text { the data, and the labelling of students (e.g. at risk) as a results of data analytics? } \\
\text { Uses of data and the questions it can answer } \\
\text { Interpreting statistics or other numeric measurements derived from students' data? } \\
\text { Limitations of learning analytics, and dangers of inferring a label from a digital footprint } \\
\text { Combining your own data sources and doing some analysis. }\end{array}$ \\
\hline
\end{tabular}

Educational Developers in Ireland Network (EDIN). One student focus group was also run at each campus, with the exception of the Blanchardstown campus of TU Dublin where timetable conflicts necessitated two focus groups. Each focus group had between 4 and 12 participants, to maximize the opportunity for all participants to share their thoughts and perspectives [4]. Consent to participate was obtained by focus group facilitators in advance, for which a Participant Information Sheet was provided.

Student participants were recruited on a voluntary basis via both the Student Union's class representatives and Course Coordinators / Tutors. Each campus focused on different academic disciplines to ensure a range of disciplines were represented. Participants were all over 18 years of age and represented undergraduate and postgraduate students from Business, Marketing, Computing, Creative Digital Media, and Science.

Staff were recruited on a voluntary basis via email. Three campuses focused on different academic disciplines. The fourth campus focused on colleagues from a range of Professional Services. Thus participating staff came from a range of departments and functions including Business, Computing, Creative Digital Media, Science, ICT, Communications, Careers, Library, Quality Assurance, Disability Services, Counselling and also Educational Developers (via EDIN).

\subsection{Qualitative Data Analysis Methods}

Focus group recordings were transcribed using rev.com transcription services, and verified by the focus group facilitator and participants. The full transcript for each focus group was used. Each idea was considered one unit [7], resulting in 676 units in total. One contribution may map to more than one unit. Thematic coding rounds utilized an inductive (bottom-up) process [2]. A categorization structure evolved from similar themes within the transcripts. The first round labeled units with corresponding categories. A second-level of analysis (second round) re-structured this initial tree code; small labels were submerging into related subcategories. That resulted in a two level structure of categories and subcategories. A third round specifically focused on training and professional development requirements. The category Training, covered training needs, requirements, gaps in knowledge, interests, and concerns.

Codification of focus group transcripts was done by two researchers working independently, using NVivo. One researcher worked on staff transcripts and one on student transcripts. A sample of 246 units, sampled across all transcripts, was reviewed by the third researcher. This sample size ensured a 95\% confidence level and a $5 \%$ confidence interval. Based on Cohen's Kappa $(\kappa)$, the level of agreement was moderate in both cases $(\kappa=0.431$ for staff transcripts; $\kappa=0.427$ for student transcripts). Acknowledging a lack of consensus on cutoffs for intercoder reliability for semi-structured focus groups, we considered this moderate result sufficient to continue with the next phase of confirming stakeholder perspectives via a survey $[3,10]$.

\subsection{Survey Administration \& Participants}

Two anonymous online surveys were disseminated across HEIs in Ireland, one to staff and one to students. Both surveys were hosted on Google Forms. Consent to participate was sought via an 
opening question on each survey, placed at the end of participant information details. Only respondents that gave consent to use their data in reports and publications were considered. Staff responses were anonymous. Students had the option of providing an email address to be included in a draw for five $£ 20$ Amazon vouchers. Email addresses were deleted once the draw had taken place.

Responses to the student survey were collected between February 18th and June 15th, 2020. A small number of students responded more than once. Where responses from the same email address had the same scores in every attempt, one response was kept. Otherwise multiple responses from the same email address were deleted. This resulted in 1,390 individual responses in total. All were aged over 18. Responses from TU Dublin made up 62\% (867) of all responses, $36 \%$ (504) of responses were from GMIT, $1 \%$ (8) were from other Irish HEIs, and 1\% (11) selected 'other'.

The staff survey was administered between January and June 2020 resulting in a total of 160 responses. The majority of respondents were from TU Dublin (67\%) and GMIT (24\%). There was good gender balance amongst respondents, $50 \%$ identified as male and $46 \%$ as female. Most respondents were academic or teaching staff (89\%). Of those, $29 \%$ were assistant lecturers and $54 \%$ were lecturers. They came primarily from four disciplines, Engineering (28\%), Business (21\%) Science (21\%), and Arts \& Humanities (10\%). Professional services (8\%), ICT services (2\%) and Library (1\%) staff were also represented.

\subsection{Survey Items and Analysis Methods}

Following focus group analysis (discussed in Section 4.2), two items were added to the student survey on training, namely: My college should provide students with training on their rights with respect to data collection and analytics; and My college should provide me with training on how to correctly interpret a dashboard showing data about my own online activity. These followed the same format as items on SHEILA's student survey (SELAQ); each statement was rated using two 7-point Likert scales covering ideal expectations ("Ideally, I would like this to happen") and predicted expectations ("I expect this to happen in reality").

Items added to the SHEILA TSELAQ survey for staff are discussed in detail in Sections 4 and 5 in the context of focus group analysis results. In summary, three items were added. The first asked staff to rate 12 training topics (listed in Figure 1). Statements were rated using a 5-point Likert scale of very useful, somewhat useful, neutral, slightly useful, not useful. The second item listed six modes of training delivery to choose from, as listed in Table 4. A third question assessed the level of engagement in learning analytics to date via seven statements with a binary 'yes' / 'no' answer, to add context to training requirements (see Table 5).

Analysis of both surveys used descriptive statistics including frequencies and percentages. Spearman's rank-order correlations $\left(r_{s}\right)$ for ordinal attributes were also calculated. However, low variance in responses may mean correlations are overestimated [13].

\section{RESULTS OF FOCUS GROUP ANALYSIS}

Staff focus groups and student focus groups are discussed separately first, and then compared. Themes are discussed in order of frequency of occurrence $(f)$. Underlined phrases aim to illustrate the key points that informed items added to surveys and the CPD framework, and are summarised again in Table 3.

\subsection{Exploring Staff Perspectives on Learning Analytics Training}

There were 122 occurrences of training related topics during staff focus groups. These related to training on: GDPR, ethical issues, and anonymity $(f=54)$; using data (e.g. feedback, module design, and teachers' performance) $(f=37)$; acting on data within a pedagogical context $(f=23)$; and how to manage feeling overwhelmed about data $(f=8)$. There were an additional 38 occurrences related to modes and duration of training.

4.1.1 Training on legal and ethical issues. Discussions on legal and ethical issues focused on understanding clearly the usefulness and the limits of what can be done ethically, and within the law. The following quotes by academic staff typify confusion related to what, and how much, data can be collected and retained.

"One of the principles of GDPR is that you only gather as minimal amount of data as you need. You don't gather lots of data on the basis that ... it might potentially be useful. So...how do we set a baseline for what is the minimum amount of data that we do need, as opposed to let's just take a whole pile and see what we get."

"But it's two different things. It's that, are you capturing that data anyway? And then, where does the ethics fit in? Is it before ... you say, "I'm going to capture library attendance." ... Is that where your ethics application comes in? ...Or is it when somebody takes that data and creates a project and starts? Is it every individual project needs ethical oversight then, once you start to drill in and ask different questions of the data?"

There was also some confusion on data access and anonymity. Professional services staff specifically would welcome more clarity on who can have access to sensitive information, and when consent is needed. For example,
"...my major concern would be around the sensitivity, so sensitive information, who has access to that, do they need access, should there be student consent"
“...there's certainly big concerns among the librarians in relation to tracking students withdrawal patterns, their borrowing records. So, for example, if you've been borrowing books on Karl Marx, does that mean you're of a communist disposition?"

4.1.2 Training on using data. Staff were interested in learning analytics for feedback and course design, but were concerned about the impact on workload and how it will be resourced. They were open to training on how to use data, but were concerned about expectations of having to learn how to process and analyze data. This position was followed by a feeling of being overwhelmed by data, not only how to get it, but also how to use it in a timely manner.

"Is there a case to be made that if there was up-skilling needed, that it's about the interpretation of table and data, rather than the generation? Because I have a bit of a concern about role expansion. I'm not entirely sure 
that it's my job to become a data generator and analyst on top of everything else that I do. So, is it somebody's role within the Institute to generate that? I'm happy to be told how to read it but I think we all have other things to be doing." (Academic staff member)

"This is where I think the college doesn't facilitate this. The college wants feedback, but they won't give the resources to support it. " (Academic staff member)

Academic developers were in strong agreement that training should be done from a pedagogical perspective, and should consider the nuanced pedagogical context within which data is generated. Their perspective is captured in the following quotes:

"Where do we start to bring those conversations and challenges from the pedagogical perspective into that? And then how do we translate that? Because that would be a very useful thing to have when you're going into programs for instance, and talking about the use of analytics, and bringing that [pedagogical perspective]"

"... it's just so nuanced and it is so context-sensitive, that I think it has to start with some sort of dialogue about what it is, what it's going to mean in different places, what's important.'

4.1.3 Training modes $(f=38)$. This subcategory encompasses a variety of expectations from staff. They said training relating to teaching innovations would be useful, but also emphasized training should be short, and provided along with ongoing support in both data interpretation and acting on data in innovative ways.

"If there's training for this and it was two hours and it got to the meat of it, that's all I need. Somebody else who wanted to do, [could] spend a whole afternoon, just different people need different levels. But I think forcing everybody through the same training programme is a mistake." (Academic staff member)

"I think maybe more than three hours of training once a year for the staff. Have ongoing discussions where people can come in, ask questions, and discuss stuff, let's say twice a term." (Academic staff member)

"I think that having real time information can be useful....there would need to be support there for people to know how to use it." (Academic staff member)

\subsection{Exploring Student perspectives on Learning Analytics Training}

In general, students were less interested in training than staff, and were more concerned about staff training than student training. The following captures their perspectives on both student and staff training. In contrast to staff, topics related to using data had higher frequency than legal or ethical considerations, and so are discussed in that order.

4.2.1 Student perspectives on training for students. As part of discussions on students' own use of learning analytics $(f=48)$, students considered it interesting to be able to understand information from learning analytics, but differed on the importance of training as the quotes below illustrate. They also believed training must be embedded within their programme of study, not an additional activity.

Facilitator: "Should you get training on interpreting statistics or other numerical measurements just derived from your own learning data?"

Student: "Like absolutely. Because especially in science, like we do an awful lot of Stats modules and stuff like that. And it's very important not just for yourself but as one of your core modules or as your core component in your course. So absolutely then. There's no point in showing people statistics or graphs or figures or trends if they don't understand them. So it should definitely be, but then again as we said it can be included in the other modules at the beginning."

Student: "I don't think it would be $100 \%$ vital, but it would be interesting, and it could be useful in some situations, but again with integrating it into an actual course would be better than something that pops up in the college. Like in Orientation in first year. If you're given an introduction on how to analyze these things, figure these things out. But I agree that I don't think it would be hugely important, but it would be interesting."

Discussions on students rights with respect to their data $(f=42)$ highlighted both a lack of awareness and a lack of interest in GDPR, with some exceptions from students in technological disciplines.

"I' $m$ actually not aware of any rights regarding the data collection from either third party, first party or whatever..."

"I actually haven't, that's the first time I've heard this term." [term is GDPR]

"it was never something that I really thought about."

"We don't talk about those things. And there is no, I didn't see any interest."

Students were concerned about data access and consent, and the comments below on anonymity and consent suggest some training on students' rights would be useful.

"I would like to know how you protect my data."

"I'd rather my data be assigned anonymously to a random number generated, that only I know or only that the computer knows. Not that someone that set up the [LMS] system knows because they could have access to countless people's data and in the future hypothetically someone gets famous and then they release that data.'

"I think it's very important though that you make sure that at the start of every year that everyone has consented. That, if something like that does happen, that after a certain amount of days, be it thirty days or something where they haven't been active on Blackboard or anything, or they haven't been seen in College at all, that there is consent that a lecturer can be notified and contact you."

4.2.2 Student perspectives on training for staff. Students were more concerned about academic staff being trained in using learning analytics $(f=19)$, particularly in the context of data for feedback 
which was their most mentioned use of learning analytics $(f=157)$. The following quote captures this perspective.

"Well, I mean, I'd hope that any lecturer that is gathering and analyzing data that they would have the technical skills to be able to perform you know, be actually doing the correct methods and be able to understand what they are looking at exactly. So we wouldn't want somebody going onto an excel sheet or using the power of AI and then not being able to understand the information that they are looking at. So just technical training, firstly, would be the most important."

Students were also concerned about data inaccuracy causing misinterpretation of learning data $(f=21)$.

"Yeah, I don't object to anything, but again.... can't speak for it being accurate in any form. Like, just say take the library [data]; some people prefer to study at home, so I don't think it's reflective of you as a student."

\subsection{Focus Group Triangulation}

Both staff and students considered training was necessary for front line staff, particularly on topics related to acting on data, interpreting visualisations, and using data appropriately. Staff mentioned their need to be trained in learning analytics several times. Their perspective was that learning analytics is something "complex" and requires lots of work and good definitions, concurring with PriceDennis and Lang [19] on the challenge of demystifying a process generally regarded as complex. While students would appreciate being taught to read and interpret their data, they put more emphasis on training for their lecturers and support staff to ensure correct use and interpretation of data.

Staff were concerned about training related to legal and ethical compliance also. However, the consensus amongst students for GDPR related training was not as strong, although students were concerned about access and consent. Only academic developers from the EDIN network regarded policy and institutional definition of learning analytics to be important. However, the importance of this as a training topic is evident from knowledge and good practices in universities worldwide which have established their definition, code of practice, and policy as the first stage of learning analytics [21,22]. Table 3 summarises how terms underlined above subsequently informed survey items and the CPD framework itself.

\section{RESULTS FROM SURVEY ANALYSIS}

Following from focus group analysis, the next phase of the methodology aimed to capture the opinion of a wider audience on training related themes that emerged from focus groups. The following sections discuss relevant survey items and responses.

\subsection{Staff survey}

5.1.1 Training items added to survey. Participants were asked to evaluate 12 statements on training needs. Focus group themes, as underlined in Section 4 and summarised in Table 3, generated 11 of these statements. They covered three categories, GDPR \& ethics, using data, and policy. The statements were cross checked with the stages of a learning analytics process depicted in Table 1 to ensure statements captured all stages (referred to in following sections as stage 1 to stage 4 ). The resulting statements are listed in Figure 1 along with their corresponding topic from Section 4 and stage from Table 1. The statement "What Learning Analytics means / is" was also included.

Figure 1 includes the percentage of positive responses to each training statement, where positive was calculated as the sum of 'very useful' and 'somewhat useful' on the 5-point Likert scale. A more detailed breakdown of responses is given in Figure 2, grouped by category (GDPR \& ethics; using data; and policy). Within each category, results are ordered based on their score for 'very useful'. Color coding maps statements to stages as listed in Figure 1. Spearman rank correlations between responses to the 12 statements were all statistically significant, and in the range [0.31, 0.78].

To further explore opinions on training options, participants were asked to choose all preferred training modes covering synchronous and asynchronous delivery, and choices on accreditation. These are listed in Table 4. Thirdly, to help put a context on responses to training statements, respondents were asked 6 questions related to perceived levels of data literacy and their institutes preparedness to adopt learning analytics. The statements and responses are listed in Table 5, and suggest individuals are more prepared than their institutions. The following sections elaborate on survey responses. The notation S1 to S12 will be used to reference training statements as numbered in Figure 1.

5.1.2 Training statements relevant to Using Data (6 statements). The most popular statement was on pedagogical response (stage 4), namely training on how to act on information from data analysis (S12, positive: $87 \%$; very useful: $56 \%$ ). The next most popular statements on using data were how to correctly interpret data visualisations (S11) and how to assess data quality (S8) (positive: $81 \%$ for both; very useful: $55 \%$ and $52 \%$ respectively), both related to explaining patterns (stage 3 ). Statements from early process stages, namely how to identify questions that data can answer (S7, 80\% positive, $48 \%$ very useful), and understanding the limitations of data (S3, positive: $77 \%$, very useful: $46 \%$ ) were marginally less popular. However, respondents were generally confident in both areas; $77 \%$ said they were comfortable identifying questions that data can answer, and $80 \%$ believed analysis was useful even when data lacked the full context for each student (see Table 5).

Echoing concerns expressed during focus groups about workload, training on how to create visualisations was also less popular (S10, positive: $78 \%$; very useful: $46 \%$ ), although the correlation between responses to this statement and how to interpret visualisations was strong $\left(r_{s}=0.78\right)$, and $65 \%$ of respondents said they had done some analysis of data collected from classroom activities.

5.1.3 Statements relevant to GDPR \& Ethics. Topics related to GDPR and ethics had the highest occurrences in focus group analysis. Corresponding statements also had the highest response for 'very useful' in staff surveys, although differences between these, and popular statements on using data, were negligible. There was little difference in the opinion of the three most useful statements in this category. They were related to: what data can we use and for what (S2, positive: $80 \%$, very useful: $59 \%$ ); how to ensure data analysis is GDPR compliant (S5, positive: $80 \%$, very useful: $58 \%$ ); and ethical and moral considerations (S4, positive: $79 \%$, very useful: $56 \%$ ). The 
Table 3: Mapping focus group topics to survey statements and CPD framework

Topics for training statements on staff survey:

Topics for training statements on student survey: Topics for statements on institutional preparedness for learning analytics and training modes:

Topics brought straight to CPD framework:
Usefulness, access, limitations, ethics, legal compliance, policy, data quality / inaccuracy, anonymity, how to use data, process, analyse, interpretation pedagogical perspective / acting on data students rights, understanding information

Interpretation, acting on data, data processing, overwhelmed by data, training should be short

Feedback, course design, impact on workload correlation between the statement on GDPR compliance and on ethical and moral considerations was strong $\left(r_{s}=0.78\right)$, but both statements had moderate correlations with the response on what data can we use (S2) ( $r_{s}=0.58$ and $r_{s}=0.61$ respectively), which may have been regarded as about using data rather than legal or ethical considerations. Interestingly, $61 \%$ of respondents said they understood what they can legally and ethically do with student data (see Table 5). So while ethical and legal training was considered very useful, it was also understood by over half of the respondents, contrasting with focus group sentiments. The final statement on how to anonymise data (stage 2) was not as popular (S9, positive: $74 \%$, very useful: $42 \%$ ), again echoing concerns about increased workload for staff.

5.1.4 Statements on Policy and What is Learning Analytics. Again concurring with focus groups, training on policy was not as popular as other topics (S6, positive: $71 \%$, very useful: $36 \%$ ) in spite of the role of policy in protecting staff and students from data misuse. It also had the lowest correlations with other responses ( $r_{s}$ range for S6 with other statements: [0.31, 0.57]). Just $43 \%$ of respondents believed their HEI had appropriate policies in the place for analysis of student data. Thus an emphasis in training on the importance of policy may be warranted.

There was also less interest in introductory training on what learning analytics is / means (S1, positive: $71 \%$, very useful: $44 \%$ ). This may suggest a bias in the sample towards those who already have some knowledge of learning analytics as indicated in Section 5.1.2. In addition, $93 \%$ believed 'it was possible to collect data about student learning that can inform teaching practices' (see Table 5). Responses to $\mathrm{S} 1$ were strongly correlated with limitations of data (S3) $\left(r_{s}=0.69\right)$ and what data can we use (S2) $\left(r_{s}=0.64\right)$, all stage 1 statements related to promoting curiosity.

5.1.5 Preferences for training delivery modes. Of the six options listed for training delivery modes, the most popular were asynchronous online resources (63\%) and face to face workshops (56\%). Accredited training was less popular as illustrated in Table 4, particularly professional development badges. A reluctance to engage in accredited training concurs with focus group results on keeping training short, complemented by ongoing support.

\subsection{Student survey results}

Two key themes emerged from student focus groups that related to training as discussed in Section 4.2, and listed again in Table 3. These were training in students' rights with respect to data collection and analysis, and how to correctly interpret a dashboard depicting their own data. As explained in Section 3.4, the student survey included a statement on each, and results are given in Figure 3. Taking agreement as a response of 5 or higher on the 7-point Likert scale, $86 \%$ agreed their college should provide training on their rights and $56 \%$ expected such training. Similarly, $83 \%$ agreed training should be provided on interpreting a dashboard and 53\% expected this training. Students' expectations concurred across both topics $\left(r_{s}=0.75\right)$ but there were differences in responses to what training they would ideally like $\left(r_{s}=0.56\right)$ showing different preferences amongst the respondents. The higher ranking for training with respect to students rights contradicted sentiments in focus groups. This suggested a focus on students' rights, rather than the GDPR prompt used in focus groups, may be more appropriate for students.

Table 4: How should training be delivered? The mean number of options selected was 2.5 .

\begin{tabular}{ll}
\hline Statement & Selected by: \\
\hline Online repository of resources that I can access & $63 \%$ \\
in my own time & \\
Face to face workshops/seminars & $56 \%$ \\
Online seminars (webinars) & $46 \%$ \\
Accredited professional development & $44 \%$ \\
A series of professional development badges & $23 \%$ \\
A MOOC (massive open online course) & $17 \%$ \\
\hline
\end{tabular}

\section{DEVELOPMENT OF A CPD FRAMEWORK}

\subsection{Summary of Training Needs}

Overall there was a strong interest in CPD for learning analytics adoption in both focus groups and survey responses. All training themes that emerged from focus groups were also deemed useful in survey results, the lowest positive score across training statements was $71 \%$. There was a preference for training in acting on data / pedagogical response (stage 4). Understanding the outputs of learning analytics (stage 3) was also popular. A third priority for training was on ethics and privacy to ensure data analysis and resulting actions are GDPR compliant and transparent. Related to this, training on appropriate uses of data was also considered a priority (stage 1).

There was less interest in training on how to analyze data (stage 2), which concurs with concerns about workload. A related theme in focus groups of feeling overwhelmed by data merits consideration in a CPD plan, to ensure a focus on how data usage can seamlessly 


\begin{tabular}{|c|c|c|c|}
\hline $\begin{array}{l}\text { Statements: Would training in the following } \\
\text { areas be useful to you? }\end{array}$ & $\begin{array}{l}\text { Category } \\
\text { (from focus group analysis) }\end{array}$ & Workflow Stage & Positive response \\
\hline 1. What learning analytics means / is & & $\begin{array}{c}\text { Stage 1: } \\
\text { Curiosity, }\end{array}$ & $71 \%$ \\
\hline 2. What data can we use and what can we do with it? & $\begin{array}{l}\text { GDPR, ethical issues: usefulness, } \\
\text { access }\end{array}$ & questions, data & $80 \%$ \\
\hline 3. Understanding the limitations of data & Using data: limitations of data & & $77 \%$ \\
\hline $\begin{array}{l}\text { 4. Ethical and moral considerations of analysing } \\
\text { student data }\end{array}$ & GDPR, ethical issues: ethics & & $79 \%$ \\
\hline $\begin{array}{l}\text { 5. How to ensure analysis of data is GDPR compliant, } \\
\text { and when is consent needed }\end{array}$ & $\begin{array}{l}\text { GDPR, ethical issues: legal } \\
\text { compliance }\end{array}$ & & $80 \%$ \\
\hline 6. Which policies are relevant and who is responsible & Policy & & $71 \%$ \\
\hline $\begin{array}{l}\text { 7. How to identify questions that learning analytics can } \\
\text { answer }\end{array}$ & Using data: usefulness & & $80 \%$ \\
\hline 8. Assessing the quality of data & Using data: data quality / inaccuracy & $\begin{array}{l}\text { Stage } 2 \text { \& 3: } \\
\text { Process and }\end{array}$ & $81 \%$ \\
\hline $\begin{array}{l}\text { 9. How to anonymise or pseudo anonymise data, and } \\
\text { when is that needed }\end{array}$ & GDPR, ethical issues: anonymity & explain pattems & $74 \%$ \\
\hline 10. How to create visualisations from my own data & Using data: how to use data & & $79 \%$ \\
\hline 11. How to correctly interpret visualisations of data & Using data: data interpretation & & $81 \%$ \\
\hline $\begin{array}{l}\text { 12.How to act on information from analysis of student } \\
\text { data }\end{array}$ & $\begin{array}{l}\text { Using data: pedagogical perspective / } \\
\text { acting on data }\end{array}$ & $\begin{array}{c}\text { Stage 4: } \\
\text { Pedagogical } \\
\text { response }\end{array}$ & $87 \%$ \\
\hline
\end{tabular}

Figure 1: Training statements, their category and stage, and percentage for positive responses (very useful + somewhat useful). Statements are numbered by the order they appeared on the survey.

Table 5: Percentage of 'yes' responses to seven statements on data literacy and preparedness (Yes / No).

\begin{tabular}{ll}
\hline Statement & Yes (\%) \\
\hline $\begin{array}{l}\text { I believe it is possible to collect data about student learn- } \\
\text { ing that can inform teaching practices. }\end{array}$ & $93 \%$ \\
$\begin{array}{l}\text { While all analysis of student data will lack the full con-- } \\
\text { text for each student, some analysis is useful. }\end{array}$ & $80 \%$ \\
$\begin{array}{l}\text { I am comfortable identifying questions about my teach- } \\
\text { ing practice that data analysis can answer. }\end{array}$ & $77 \%$ \\
$\begin{array}{l}\text { I have done some analysis myself on data I collect from } \\
\text { classroom activities. }\end{array}$ & $65 \%$ \\
$\begin{array}{l}\text { I understand what I can legally and ethically do with } \\
\text { student data. }\end{array}$ & $61 \%$ \\
$\begin{array}{l}\text { I believe my college has the appropriate infrastructure } \\
\text { to collect relevant data. }\end{array}$ & $51 \%$ \\
$\begin{array}{l}\text { I believe my college has appropriate policies in place to } \\
\text { cover analysis of student data. }\end{array}$ & $43 \%$ \\
\hline
\end{tabular}

fit into existing activities, rather than become an additional job or source of stress. There was also less interest in training related to policy, with the exception of educational developers for whom it was a key priority. This suggests CPD has a role in explaining the importance of policy in ensuring good practice in learning analytics.

\subsection{A CPD Framework}

Based on these results, we propose the CPD framework illustrated in Figure 4. Dividing stakeholders into three groups, the columns identify three target audiences, namely: students; professional services staff; and academic staff. In some cases, topics are shown as being common across all three. However, it is envisaged that while the content may be similar, training should be adapted to each target group to ensure it is delivered through stories and use cases that capture contexts related to each audience.

Rows divide topics into three sections. The first is 'Knowing' about learning analytics and its possibilities and limitations. Its focus is promoting curiosity about the questions that learning analytics can answer while providing clarity on ethical constraints and good codes of practice, the importance of learning analytics policy, and the types of data available to each group. Secondly, 'Using and practicing' focuses on topics relevant to working with data. Topics include data access \& capture, data processing \& interpretation and learning analytics for feedback. While covering both stages 2 and 3 from Table 1, an emphasis on sense making rather than processing reflects the reluctance by front line staff to embrace generating their own analytics. The third category focuses on 'taking action', covering action and impact, promoting agency, and considering how this can take place within current work practices and resource limitations (stage 4).

\subsection{Discussion}

The CPD framework presented here extends existing models of the learning process discussed in Section 2 by also incorporating 

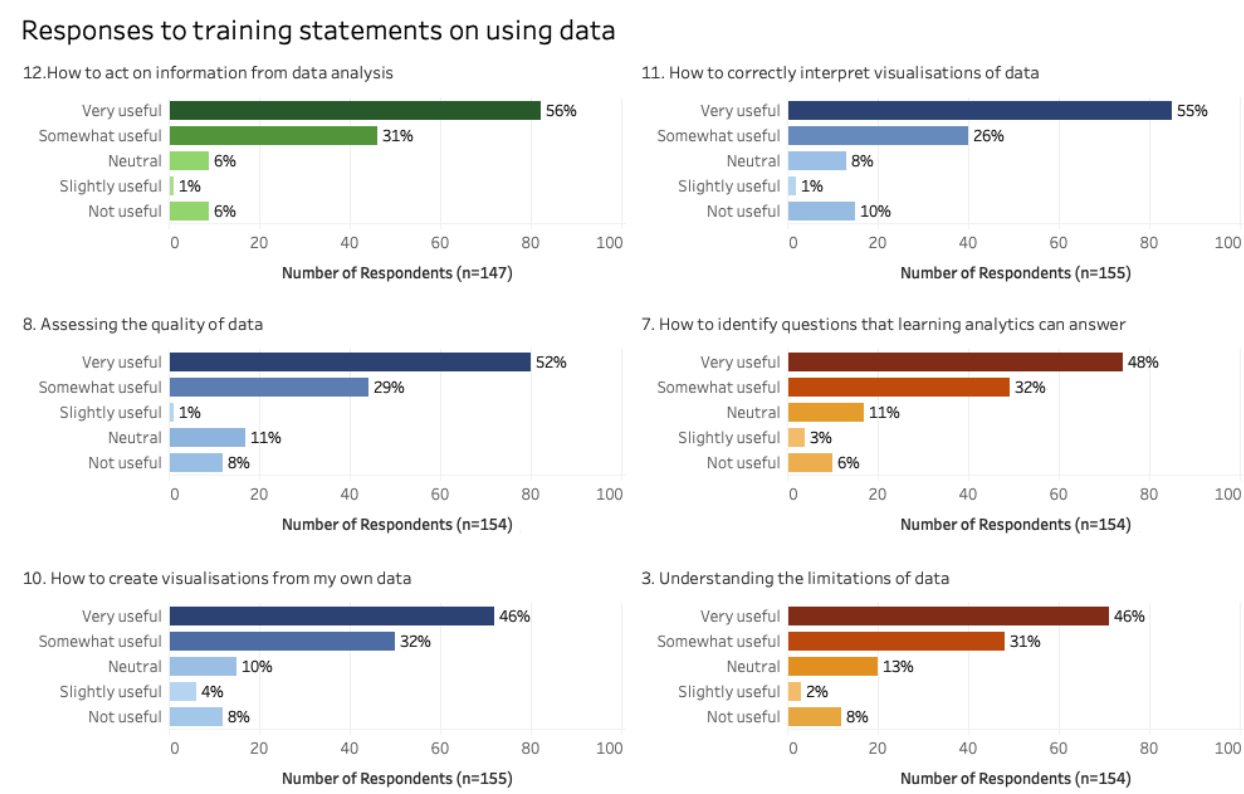

Responses to training statements on GPPR and ethical issues
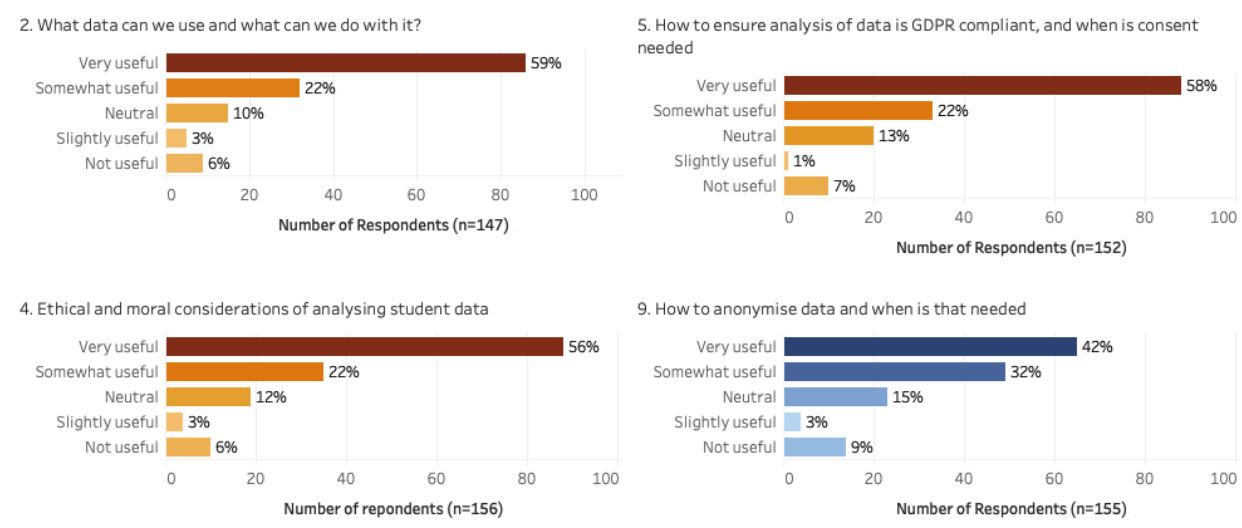

Training statements on Policy and What is learning analytics
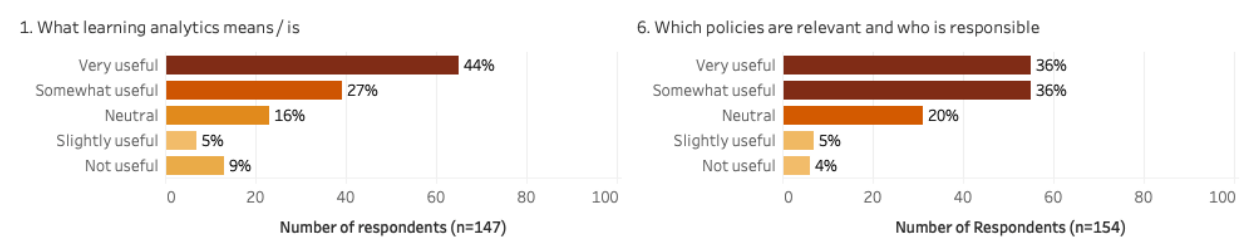

Figure 2: Breakdown of staff responses to training statements by category, and colour coded by stage. Orange relates to promoting curiosity, blue relates to processing and explaining patterns, and green relates to pedagogical response.

aspects of learning analytics not directly associated with using data, namely legal and ethical implications of analysing student data, the importance of policy, and impact on workload. It also differentiates between training needs of students, academic staff and professional services staff.

Stakeholders' perspectives that informed this framework were primarily students and academic staff in higher education in Ireland. We acknowledge this is a limited context, and further work is needed to see if these perspectives are reflected in other contexts. In addition, this study represents a point in time, and HEIs that are in early stages of learning analytics adoption. Ongoing review of learning analytics CPD requirements needs to reflect developments in both research and practice.

The importance of context in the learning process means that learning resources addressing areas of this framework need to be developed in a manner that connects data to its context. Given the variety of both instructional and learner contexts to be considered, development of training resources is likely to be an iterative and evolving process. This development must address the challenge of providing bite sized resources that are meaningful and relevant 


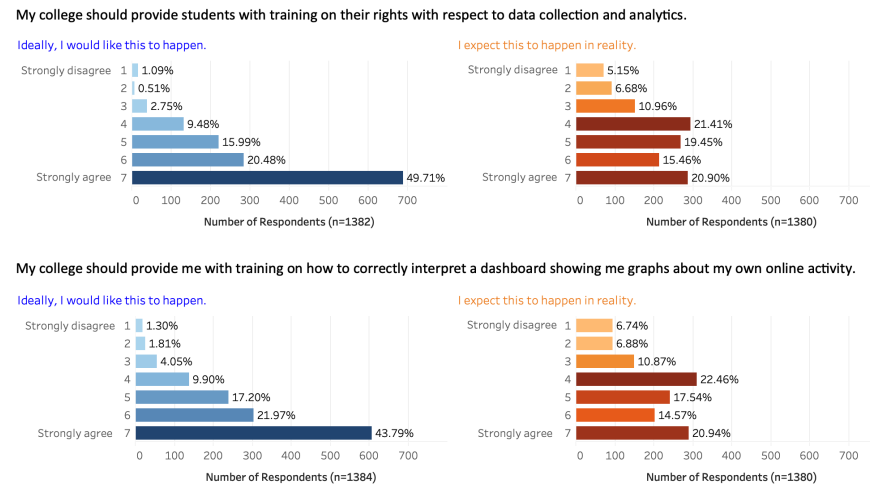

Figure 3: Students ideals and expectations for training.

across contexts, while addressing complex issues of ethics, legal constraints, and robust critiques of inferences derived from data. Further research is needed to assess the impact of the Framework and corresponding resources in developing personal, professional and institutional capacity in learning analytics. The next step for this project is to develop resources for evaluation by stakeholders.

There were many topics raised by stakeholders and consequently included in the framework. However, the success of such a framework is dependent not only on the quality of the educational resources developed to enact it, but also on ongoing support for stakeholders. For example, staff reported feeling overwhelmed by data, and under equipped to derive actionable intelligence from it. Similarly, there were concerns expressed about data quality, and its impact on resulting models. On the other hand, there was a requirement for training to be short, and not to assume an expansion of responsibilities. CPD alone will be insufficient to enable more effective use of learning data. Staff also require ongoing support in multiple related areas including the technical skills needed to process data, the interpretive skills needed to make sense of data within a wider, nuanced context, and enacting appropriate interventions to enhance student support. There is a balance to be struck between what can reasonably be expected of all staff in terms of data literacy and what additional support should be provided.

\section{CONCLUSION}

This paper reports on a study that developed a CPD framework for learning analytics based on feedback on training requirements from stakeholders. Specifically, it addressed the question: What are the constituents for a CPD framework based on staff and student needs? Stakeholder perspectives were collected using focus groups and surveys in Irish HEIs. A review of literature suggested data collection instruments should focus on training in: using, interpreting and acting on data; GDPR and ethics; policy; and boundaries between the role of front line staff and the role of a learning analyst. This was accomplished by augmenting the SHIELA framework protocols to include additional items on training. Analysis of stakeholder feedback highlighted that students were less interested in training than staff, but would welcome training on how to interpret dashboards, and their rights with respect to analysis of their data. Students also emphasised the importance of staff training on correct use and interpretation of data. Staff prioritize acting on data and correct interpretation of data over being able to process data themselves. Clarification on ethical and legal uses of data in a learning analytics context was also a priority.

The resulting CPD framework presents three levels of training. Level 1, knowing, focuses on ethics and privacy, risks and limitations of data, appropriate uses of data for different stakeholders, and the role of learning analytics policy. Level 2, using and practicing focuses on data interpretation, data access, data quality, and using data for feedback. Level 3, taking action, focuses on action and reflection. The framework differentiates between the training requirements of different stakeholder groups, namely students, academic staff and professional services staff. Implementation of such a framework would need to consider concerns expressed by staff over increased workload, and a requirement for short training resources backed up with ongoing support from a learning analytics function. In addition, training requirements would need to be revisited overtime in line with developments in both research and practice in this field.

\section{REFERENCES}

[1] Stephen J. Aguilar and Clare Baek. 2019. Motivated Information Seeking and Graph Comprehension Among College Students. In Proceedings of the 9th International Conference on Learning Analytics \& Knowledge. ACM, Tempe, Arizona, 280-289.

[2] Virginia Braun and Victoria Clarke. 2006. Using thematic analysis in psychology. Qualitative Research in Psychology 3, 2 (Jan. 2006), 77-101. https://doi.org/10.1191/1478088706qp063oa Publisher: Routledge _eprint: https://www.tandfonline.com/doi/pdf/10.1191/1478088706qp063oa.

[3] John L. Campbell, Charles Quincy, Jordan Osserman, and Ove K. Pedersen. 2013. Coding in-depth semistructured interviews: Problems of unitization and intercoder reliability and agreement. Sociological Methods \& Research 42, 3 (2013), 294-320. Publisher: Sage Publications Sage CA: Los Angeles, CA.

[4] Benedicte Carlsen and Claire Glenton. 2011. What about N? A methodological study of sample-size reporting in focus group studies. BMC Medical Research Methodology 11, 1 (March 2011), 26. https://doi.org/10.1186/1471-2288-11-26

[5] Cassandra Colvin, Shane Dawson, Alexandra Wade, and Dragan Gasevic. 2017. Addressing the challenges of institutional adoption. In Handbook of learning analytics (1 ed.), Charles Lang, George Siemens, Alyssa Wise, and Dragan Gasevic (Eds.). Society for Learning Analytics Research, 281-289.

[6] Linda Corrin and Paula De Barba. 2015. How do students interpret feedback delivered via dashboards? In Proceedings of the fifth international conference on learning analytics and knowledge. ACM, Poughkeepsie, NY, 430-431.

[7] Jason W. Davey, Fenwal Inc, P. Cristian Gugiu, and Chris L. S. Coryn. 2010. Quantitative Methods for Estimating the Reliability of Qualitative Data. Fournal of MultiDisciplinary Evaluation 6, 13 (2010), 140-162.

[8] Shane Dawson, Srecko Joksimovic, Oleksandra Poquet, and George Siemens. 2019. Increasing the Impact of Learning Analytics. In Proceedings of the 9th International Conference on Learning Analytics \& Knowledge. ACM, Tempe AZ, 446-455. https://doi.org/10.1145/3303772.3303784 Pages: 455.

[9] Suzanne L. Dazo, Nicholas R. Stepanek, Aarjav Chauhan, and Brian Dorn. 2017. Examining instructor use of learning analytics. In Proceedings of the 2017 CHI Conference Extended Abstracts on Human Factors in Computing Systems. 25042510.

[10] Lopez de Ullibarri Galparsoro and S Pita Fernandez. 1999. Medidas de concordancia: el indice Kappa. Cad Aten Primaria 6 (1999), 169-171. https: //www.fisterra.com/mbe/investiga/kappa/kappa.asp

[11] TU Dublin. 2020. Evidence Based Decision Making in the Classroom. https: //www.youtube.com/watch?v=GB PVj_i4cQ

[12] Dragan Gasevic, Shane Dawson, Tim Rogers, and Danijela Gasevic. 2016. Learning analytics should not promote one size fits all: The effects of instructional conditions in predicting academic success. The Internet and Higher Education 28 (Jan. 2016), 68-84. https://doi.org/10.1016/j.iheduc.2015.10.002

[13] Laura D. Goodwin and Nancy L. Leech. 2006. Understanding Correlation: Factors That Affect the Size of r. The fournal of Experimental Education 74, 3 (2006), 251-266. https://www.jstor.org/stable/20157427 Publisher: Taylor \& Francis, Ltd.

[14] Christothea Herodotou, Bart Rienties, Avinash Boroowa, Zdenek Zdrahal, Martin Hlosta, and Galina Naydenova. 2017. Implementing predictive learning analytics on a large scale: the teacher's perspective. In Proceedings of the seventh international learning analytics \& knowledge conference. 267-271. 


\begin{tabular}{|c|c|c|c|c|}
\hline & & Students & Professional Services & Teaching staff \\
\hline Level 1 & Introduction & \multicolumn{3}{|c|}{$\begin{array}{l}\text { General and Institutional Definitions of Learning Analytics (LA). } \\
\text { Micro \& macro LA for students, professional services staff, academic staff and academic management. }\end{array}$} \\
\hline \multirow{5}{*}{ (What could I see?) } & \multirow{2}{*}{$\begin{array}{l}\text { Ethics and } \\
\text { privacy }\end{array}$} & \multicolumn{3}{|c|}{ What are student rights w.r.t. their data; what are legal, ethical and moral uses of student data. } \\
\hline & & \multicolumn{3}{|c|}{ What is good practice w.r.t. analysis of student data. } \\
\hline & $\begin{array}{l}\text { Risks \& } \\
\text { Limitations }\end{array}$ & \multicolumn{3}{|c|}{ Awareness of the potential of LA; and awareness of limitations, risks and sources of error. Impact of inaccurate data. } \\
\hline & Data & $\begin{array}{l}\text { Familiarity with data available to students and how } \\
\text { it could be used. }\end{array}$ & $\begin{array}{l}\text { Familiarity with data available to professional } \\
\text { services and how it could be used. }\end{array}$ & $\begin{array}{l}\text { Familiarity with data available to teaching staff and } \\
\text { how it could be used. }\end{array}$ \\
\hline & Policy & & The role of LA policy; principles of LA. & \\
\hline \multirow{6}{*}{$\begin{array}{l}\text { Using and practicing } \\
\text { (How could I } \\
\text { interpret LA?) }\end{array}$} & Interpretation & Interpreting student facing LA. & $\begin{array}{l}\text { Interpreting analytics relevant to professional } \\
\text { services staff. }\end{array}$ & Interpreting analytics relevant to teaching staff. \\
\hline & Access & How to access data available to students. & $\begin{array}{l}\text { How to access data available to professional services } \\
\text { staff. }\end{array}$ & How to access data available to teaching staff. \\
\hline & Quality & $\begin{array}{l}\text { How to assess data quality in data accessible to } \\
\text { students. }\end{array}$ & $\begin{array}{l}\text { How to assess data quality in data accessible to } \\
\text { professional services staff. }\end{array}$ & $\begin{array}{l}\text { How to assess data quality in data accessible to } \\
\text { teaching staff. }\end{array}$ \\
\hline & \multirow{2}{*}{ Feedback } & \multirow[t]{2}{*}{ Interpreting feedback. } & & $\begin{array}{l}\text { Teaching and assessment strategies to maximize } \\
\text { data/insight into students' progress. }\end{array}$ \\
\hline & & & & $\begin{array}{l}\text { Providing general feedback on progress; and specific } \\
\text { feedback on learning outcomes. }\end{array}$ \\
\hline & $\begin{array}{l}\text { At risk } \\
\text { students }\end{array}$ & & \multicolumn{2}{|c|}{ LA to aid identifying and supporting struggling and disengaged students. } \\
\hline \multirow{4}{*}{$\begin{array}{c}\text { Taking action } \\
\text { (What can I do with } \\
\text { LA) }\end{array}$} & Action & Acting on feedback and insights from data. & Using data to improve services. & Using data to improve teaching practice; case studies. \\
\hline & \multirow{3}{*}{ Reflection } & \multirow{2}{*}{$\begin{array}{l}\text { What kind of decisions relevant to my learning } \\
\text { process can be informed by LA? }\end{array}$} & \multicolumn{2}{|c|}{ LA to help staff in their work; Training on reflection on practice - how do I teach? } \\
\hline & & & \multicolumn{2}{|l|}{ Impact of LA on workload. } \\
\hline & & Training on reflection - how I learn? & \multicolumn{2}{|c|}{ What kind of decisions relevant to my work would be enhanced by LA? } \\
\hline
\end{tabular}

Figure 4: Framework for continuous professional development in learning analytics

[15] Christothea Herodotou, Bart Rienties, Martin Hlosta, Avinash Boroowa, Chrysoula Mangafa, and Zdenek Zdrahal. 2020. The scalable implementation of predictive learning analytics at a distance learning university: Insights from a longitudinal case study. The Internet and Higher Education 45 (2020), 100725 Publisher: Elsevier.

[16] Lisa Lim, Shane Dawson, Srecko Joksimovic, and Dragan Gasevic. 2019. Exploring students' sensemaking of learning analytics dashboards: Does frame of reference make a difference?. In Proceedings of the 9th International Conference on Learning Analytics \& Knowledge. 250-259.

[17] Ellen Mandinach, Jeremy M Friedman, and Edith Gummer. 2013. How Can Schools of Education Help to Build Educators' Capacity to Use Data? A Systemic View of the Issue. Educational Researcher 42, 1 (2013), 28.

[18] Inge Molenaar and Carolien Knoop-van Campen. 2017. Teacher dashboards in practice: Usage and impact. In European Conference on Technology Enhanced Learning. Springer, 125-138.

[19] Detra Price-Dennis and Charles Lang. 2018. Exploring Teacher Learning through STEM Teachers' Exploration of Data Using a Domain Specific Coding Language. International Society of the Learning Sciences, Inc.[ISLS]. (2018).

[20] Juan Sarmiento, Fabio Campos, and Alyssa Wise. 2020. Engaging Students as CoDesigners of Learning Analytics. Companion proceedings of the 10th international learning analytics and knowledge conference (March 2020), 29-32.

[21] Maren Scheffel, Yi-Shan Tsai, Dragan Gasevic, and Hendrik Drachsler. 2019 Policy Matters: Expert Recommendations for Learning Analytics Policy. In Transforming Learning with Meaningful Technologies (Lecture Notes in Computer Science), Maren Scheffel, Julien Broisin, Viktoria Pammer-Schindler, Andri Ioannou, and Jan Schneider (Eds.). Springer International Publishing, Cham, 510-524. https://doi.org/10.1007/978-3-030-29736-7 38

[22] Niall Sclater. 2016. Developing a code of practice for learning analytics. Fournal of Learning Analytics (April 2016), 16-42. https://doi.org/10.18608/jla.2016.31.3

[23] Kaiwen Sun, Abraham H Mhaidli, Sonakshi Watel, Christopher A Brooks, and Florian Schaub. 2019. It's My Data! Tensions Among Stakeholders of a Learning Analytics Dashboard. Proceedings of the 2019 CHI Conference on Human Factors in Computing Systems (2019), 1-14.

[24] Yi-Shan Tsai, Pedro Manuel Moreno-Marcos, Kairit Tammets, Kaire Kollom, and Dragan Gasevic. 2018. SHEILA policy framework: Informing institutional strategies and policy processes of learning analytics. In Proceedings of the 8th international conference on learning analytics and knowledge. 320-329.
[25] Yi-Shan Tsai, Carlo Perrotta, and Dragan Gasevic. 2020. Empowering learners with personalised learning approaches? Agency, equity and transparency in the context of learning analytics. Assessment \& Evaluation in Higher Education 45, 4 (2020), 554-567. Publisher: Routledge.

[26] Anouschka van Leeuwen, Margot van Wermeskerken, Gijsbert Erkens, and Nikol Rummel. 2017. Measuring teacher sense making strategies of learning analytics: a case study. Learning: Research and Practice 3, 1 (Jan. 2017), 42-58. https: //doi.org/10.1080/23735082.2017.1284252

[27] Katrien Verbert, Erik Duval, Joris Klerkx, Sten Govaerts, and Jose Luis Santos. 2013. Learning analytics dashboard applications. American Behavioral Scientist 57, 10 (2013), 1500-1509. Publisher: Sage Publications Sage CA: Los Angeles, CA.

[28] Alyssa Friend Wise and Yeonji Jung. 2019. Teaching with Analytics: Towards a Situated Model of Instructional Decision-Making. Fournal of Learning Analytics 6, 2 (July 2019), 53-69-53-69. https://doi.org/10.18608/jla.2019.62.4 Number: 2.

\section{ACKNOWLEDGMENTS}

This study was funded by the National Forum for the Enhancement of Teaching and Learning in Ireland. TU Dublin members were: Dr. Geraldine Gray, Dr. Ana Schalk, Dr. Kevin O’Rourke, Dr. Catherine Deegan, Dr. James Doody, Dr. Darvree Downey, Dr. Gordon Cooke, Rebecca Gorman (student member) and Lee Bennett (student member). GMIT members were: Phelim Murnion, Dr. Carina Ginty, Dr. Sean Daffy and Victor O'Loughlin (student member). External advisors were: Dr. Pauline Rooney, Trinity College Dublin, Lee O’Farrell, University College Dublin, and Dr. Charles Lang, Teachers College, Columbia University. 